\title{
SELENITE TRANSPORT AND ITS INHIBITION IN THE UNICELLULAR GREEN ALGA CHLAMYDOMONAS REINHARDTII
}

\author{
Hélène Morlon, $†$ Claude Fortin, $\neq$ Christelle Adam, + and Jacqueline Garnier-Laplace $\dagger$ \\ $\dagger$ †aboratoire de Radioécologie et Ecotoxicologie, Institut de Radioprotection et Sûreté Nucléaire, Cadarache, Bat 186, BP 3, \\ 13115 Saint-Paul-lez-Durance, Cedex, France \\ $\ddagger$ Institut National de la Recherche Scientifique—Eau, Terre et Environnement, Université du Québec, 490, rue de la Couronne, \\ Québec G1K 9A9, Canada
}

(Received 31 March 2005; Accepted 24 October 2005)

\begin{abstract}
The influence of time, ambient concentration, and medium composition on selenite (Se(IV)) uptake by the unicellular green alga Chlamydomonas reinhardtii has been investigated. The aims of the performed experiments were to describe the kinetics of accumulation, to characterize transport capacities, to identify key nutrients influencing absorption, and to establish links between speciation and bioavailability. Our results suggested that the adsorbed fraction was negligible compared to the absorbed one. Over the short time scale considered, the absorption was linear with time, with an estimated conductance of approximately $0.2 \mathrm{nmol} /$ $\mathrm{m}^{2} / \mathrm{h} / \mathrm{nM}$. Uptake was proportional to ambient levels in a broad range of intermediate concentrations (from nM to $\mu \mathrm{M}$ ). However, conductances were higher at low concentrations $(<\mathrm{nM})$ and then decreased with increasing concentrations $(>\mu \mathrm{M})$. These results suggested that a specific but rapidly saturated transport system was involved at low concentrations, coupled with a nonspecific one that was only saturated at high ambient concentrations $(\sim \mathrm{mM})$. The latter could involve transporters used by anionic macronutrients, which is supported by the fact that increasing sulfate and nitrate concentrations induced significant inhibition of Se(IV) uptake. Finally, Se(IV) speciation changes caused by varying $\mathrm{pH}$ did not significantly affect bioavailability.
\end{abstract}

Keywords-Oxyanions Selenium Phytoplankton Transport Inhibition

\section{INTRODUCTION}

Selenium is an essential micronutrient that is characterized by a very narrow nutritional concentration range before becoming toxic. Among other roles, selenium is required for optimal growth of many plants and algae, including Chlamydomonas reinhardtii [1]. In this unicellular green alga, a glutathione peroxidase containing selenocysteine residues at the active site is induced by selenite (Se(IV)) and acts against oxidative stress, inhibiting the damage caused by hydroperoxides $[1,2]$. Selenium is released in freshwaters primarily as inorganic forms $(\mathrm{Se}(\mathrm{IV}))$ and selenate $(\mathrm{Se}(\mathrm{VI}))$ from both natural and anthropogenic sources and is distributed unevenly in the environment. Its typical concentration in unpolluted freshwaters is in the nanomolar range [3]. It can become highly toxic to aquatic life, inducing severe environmental consequences [4]. Selenium pollution is now considered to be a global environmental issue [5]. Based on the literature for algae [6-8] and the results of our own experiments $[9,10]$, direct effects of selenium on the phytoplankton biomass are not expected to occur in the environment, because growth inhibition only appears at high dissolved Se(IV) concentrations $(\sim \mu \mathrm{M})$. However, algae can accumulate, transform, and transfer large quantities of selenium [7,8]. Recent field studies have shown that processes controlling inorganic selenium uptake at the base of the food web determine how selenium affects aquatic ecosystems [11]. Dietary proteinaceous forms of selenium are more available and more toxic to higher organisms compared with waterborne, inorganic forms $[4,12,13]$. Hence, the poisoning of the upper trophic levels in selenium-contaminated systems is thought to result from the bioconcentration of se-

\footnotetext{
* To whom correspondence may be addressed (christelle.adam@irsn.fr).
}

lenium by primary producers and the subsequent biomagnification of the more toxic, organic forms up the aquatic food chain [5]. Selenium uptake in algal cells thus is critical to its transfer and effects in aquatic ecosystems. The most significant oxidation states of inorganic selenium within the natural oxic freshwater $\mathrm{pH}$-electrochemical potential ( $\mathrm{ph}$-Eh) domain are the oxyanions $\mathrm{Se}(\mathrm{IV})$ and $\mathrm{Se}(\mathrm{VI})$; the dominance of one or the other form is determined by the initial form released to the environment, $\mathrm{pH}, \mathrm{Eh}$, and the redox reaction kinetics. It is believed, however, that selenium contents in organisms and its toxicity are principally linked to the concentration of Se(IV) in water, because this form is scavenged from water and transformed to organoselenium to a greater extent than $\mathrm{Se}(\mathrm{VI})$ [14]. In particular, both $\mathrm{Se}(\mathrm{IV})$ and $\mathrm{Se}(\mathrm{VI})$ are accumulated by algae, but $\mathrm{Se}(\mathrm{IV})$ has been shown to be accumulated more readily than $\mathrm{Se}(\mathrm{VI})$ into phytoplankton $[7,12,15,16]$, particularly at the low ambient concentrations of selenium normally found in the environment $(\sim \mathrm{nM})[14]$. We thus focused our investigations on $\mathrm{Se}(\mathrm{IV})$ uptake.

Many studies concern the biological uptake and toxicity of metals characterized by a tendency to form cationic species, but few deal with the uptake of those mainly forming oxyanions, such as $\mathrm{Se}(\mathrm{IV})$ [17]. However, the latter often are very mobile, bioavailable, and potentially toxic. Little is known about their general behavior concerning the transfer through biological membranes, but this behavior is expected to be very different from that generally known for cations. First, the adsorption to the cell wall is expected to be lower for anions than for cations because of the predominance of negatively charged groups at the cell surface, tending to attract cations while repelling anions; negatively charged groups are mainly amino and carbonyl components of structural proteins and the 
carboxyl groups of polysaccharides. This repulsion is expected to be lower in low-pH waters, because protonation of the anionic functional groups reduces the negative potential at the biological surface, facilitating adsorption. Chloride-specific ion channels generally are permeable to several other anions, but generally not to those that are the size of oxyanions. Sulfate, phosphate, nitrate, and carbonate species are transported through other poorly selective carriers. Because of their similar chemical behavior, membrane transport of contaminants forming oxyanions (molybdenum, vanadium, chromium, arsenic, antimony, and selenium) may involve these anionic transport systems [17]. Hence, nutrients in solution could directly affect the accumulation of oxyanions by competition for the same assimilation pathways [18]. Eutrophication thus can have consequences both on the phytoplankton biomass and on the accumulation of trace metals, hence modifying the pool of contaminants taken up by phytoplankton. Clearly, a need exists to study trace metal-macronutrient interactions, which may have substantial implications for our understanding of traceelement biogeochemical cycling in freshwater systems $[19,20]$. Many studies of metal accumulation or toxicity have found that the total aqueous concentration of the metal is not a good predictor of its bioavailability. Uptake generally depends on the metal's speciation, which itself depends on physicochemical parameters [21]. Thus, much research conducted in the past decades has been dedicated to prediction of the speciation of cationic metals and to establishing links between speciation and availability to aquatic organisms; predictive models, such as the Free Ion Activity Model or the Biotic Ligand Model, have resulted from these investigations. However, few studies have explored the relationships between the speciation of anionic contaminants and bioavailability, and to our knowledge, the applicability of the above models has not yet been tested for anions.

Keeping in mind the environmental interest of predicting $\mathrm{Se}(\mathrm{IV})$ fluxes in freshwater ecosystems and their dependence on the physicochemical characteristics of the medium, we studied the dependence of Se(IV) accumulation (both adsorption and absorption) on time, ambient concentration, different nutrient concentrations, and $\mathrm{pH}$ using the unicellular green alga $C$. reinhardtii as a test organism. Links between Se(IV) speciation and bioavailability, as well as possible mechanisms for the transport of $\mathrm{Se}(\mathrm{IV})$, also were investigated.

\section{MATERIALS AND METHODS}

\section{Algal cultures and experimental protocol}

Chlamydomonas reinhardtii cultures were obtained from the Culture Collection of Algae and Protozoa (culture 11/32B; Cumbria, UK). Maintenance and experimental culturing were performed axenically in modified high-salt media [22] with an ionic strength of approximately $20 \mathrm{mEq} / \mathrm{L}$ (Table 1) under constant illumination at $100 \pm 10 \mu \mathrm{mol} / \mathrm{m}^{2} / \mathrm{s}$ of photosynthetically available radiation, with an ambient temperature of $25 \pm 0.5^{\circ} \mathrm{C}$ and rotary agitation $(\sim 120 \mathrm{rpm})$. Cells in the endexponential growth phase were inoculated in the culture media by addition of the volume needed to obtain an initial density of 2,500 cells $/ \mathrm{ml}$. They were collected $48 \mathrm{~h}$ later (corresponding to the end of their exponential growth phase) by filtration on a $2-\mu \mathrm{m}$ polycarbonate filter membrane (Poretics, Minnetonka, MN, USA). The recovered cells were rinsed five times with 5-ml aliquots of selenium-free exposure medium (see below) and resuspended in $3 \mathrm{ml}$ of the same medium. They were then transferred to polycarbonate Erlenmeyer flasks con-
Table 1. Nominal concentrations of the components of the algal culture medium (modified high-salt medium adapted from Harris [22]) and of the simplified media used for the exposure experiments and to rinse the harvested cells

\begin{tabular}{|c|c|c|}
\hline \multirow[b]{2}{*}{ Components } & \multicolumn{2}{|c|}{ Culture medium (M) } \\
\hline & Algal & Simplified \\
\hline $\mathrm{NH}_{4}$ & $9.36-10^{-3}$ & $9.36-10^{-3}$ \\
\hline $\mathrm{Cl}$ & $13.5-10^{-3}$ & $13.5-10^{-3}$ \\
\hline $\mathrm{K}$ & $1.22-10^{-3}$ & $1.22-10^{-3}$ \\
\hline $\mathrm{PO}_{4}$ & $0.14-10^{-3}$ & $0-137-10^{-6 a}$ \\
\hline $\mathrm{C}_{\text {inorganic }}$ & $\sim 50-10^{-6 b}$ & $50-5,000-10^{-6} a$ \\
\hline $\mathrm{NO}_{3}$ & $2.92-10^{-3}$ & $0-30-10^{-3}$ \\
\hline $\mathrm{SO}_{4}$ & $81.2-10^{-6}$ & $0-800-10^{-6}$ a \\
\hline $\mathrm{Mg}$ & $1.04-10^{-3}$ & $1.04-10^{-3}$ \\
\hline $\mathrm{Ca}$ & $2.00-10^{-3}$ & $2.00-10^{-3}$ \\
\hline $\mathrm{Na}$ & $0.10-10^{-3}$ & $0.10-10^{-3}$ \\
\hline $\mathrm{BO}_{3}$ & $3.01-10^{-6}$ & - \\
\hline $\mathrm{Mn}$ & $2.09-10^{-6}$ & - \\
\hline EDTA $^{c}$ & $8.06-10^{-7}$ & - \\
\hline $\mathrm{Fe}$ & $5.92-10^{-7}$ & - \\
\hline $\mathrm{MoO}_{4}$ & $3.00-10^{-8}$ & - \\
\hline $\mathrm{Zn}$ & $2.43-10^{-8}$ & - \\
\hline Co & $1.09-10^{-8}$ & - \\
\hline $\mathrm{Cu}$ & $7.04-10^{-11}$ & - \\
\hline
\end{tabular}

a According to the experiment.

${ }^{\text {b }}$ Partial pressure of carbon dioxide, $3.16-10^{-4} \mathrm{~atm}$.

${ }^{\mathrm{c}} \mathrm{EDTA}=$ ethylenediaminetetraacetic acid.

taining $200 \mathrm{ml}$ of exposure medium for a short period of time $\left(60 \mathrm{~min}\right.$ ) to fixed levels of ${ }^{75} \mathrm{Se}$ (as $\mathrm{Se}(\mathrm{IV}), \mathrm{H}_{2} \mathrm{SeO}_{3}$, in 0.01 $\mathrm{M} \mathrm{HCl}$; Riso, Roskilde, Denmark), obtained by addition of the required volume of the stock solution. A 1-ml sample of solution was taken from the exposure medium before exposure for analysis of the selenium concentration. The exposure medium consisted of a simplified culture medium, without trace metals, of varying $\mathrm{pH}$ and concentrations of sulfate, phosphate, nitrate, and dissolved inorganic carbon, depending on the experiment. Short-duration experiments using low cell densities were performed to minimize changes to the exposure medium because of nutrient consumption and release of exudates. Cell densities and mean cell diameters were measured for each experiment using a Coulter Z2 particle counter (Beckman Coulter, Roissy, France). Cell densities usually were approximately 100,000 cells $/ \mathrm{ml}$, and mean cell diameter varied between 4.5 and $5 \mu \mathrm{m}$. Variations in cell size and biomass were negligible over the short exposure periods used. After exposure, cells were collected by filtration on two superimposed, $2-\mu \mathrm{m}$ filter membranes (the role of the lower membrane being to determine the quantity of $\mathrm{Se}(\mathrm{IV})$ adsorbed on the membrane filters). Half of the exposed cells were rinsed (five times with $5 \mathrm{ml}$ of selenium-free exposure medium) to remove $\mathrm{Se}(\mathrm{IV})$ adsorbed on the cell membrane, thus representing the intracellular or absorbed fraction; the remaining half were not rinsed, thus representing both adsorbed and absorbed selenium. The adsorbed fraction was estimated by the difference in selenium content between rinsed and nonrinsed cells.

Harvested cells were acid-digested in borosilicate scintillation vials at room temperature for at least $12 \mathrm{~h}$ by $1-\mathrm{ml}$ aliquots of concentrated (65\%) nitric acid. Samples were then slowly evaporated to dryness on a heated sand bed. The mineralized residues were redissolved in $1 \mathrm{ml}$ of $1 \%(\mathrm{v} / \mathrm{v}) \mathrm{HNO}_{3}$, and $19 \mathrm{ml}$ of scintillation cocktail were added (Instagel; Packard Instrument, Rungis, France). Liquid scintillation counting (detection limit, $\sim 40 \mathrm{mBq} / \mathrm{sample}$; Quantulus 1220; Wallac 
Table 2. Selenium formation and solubility product constants used, given at zero ionic strength and $25^{\circ} \mathrm{C}^{\mathrm{a}}$

\begin{tabular}{lcllcc}
\hline Aqueous complex & $\log K$ & \multicolumn{1}{c}{ References } & Solid complex & Log $K_{\text {sp }}$ & References \\
\hline $\mathrm{HSeO}_{3}^{-}$ & 8.1 & {$[25,26,37]^{\mathrm{b}}$} & $\mathrm{CaSeO}_{3} \cdot \mathrm{H}_{2} \mathrm{O}$ & 7.76 & {$[38]$} \\
$\mathrm{H}_{2} \mathrm{SeO}_{3}$ & 10.71 & {$[25,26,37]^{\mathrm{b}}$} & $\mathrm{CaSeO}_{3} \cdot 2 \mathrm{H}_{2} \mathrm{O}$ & 5.44 & {$[37]$} \\
$\mathrm{CaSeO}_{3}$ & 3.17 & {$[39]$} & $\mathrm{K}_{2} \mathrm{SeO}_{3}$ & 1.48 & {$[40]$} \\
$\mathrm{K}_{2} \mathrm{SeO}_{3}$ & 0.28 & {$[37]$} & $\mathrm{MgSeO}_{3}$ & 7.15 & {$[38-40]^{\mathrm{c}}$} \\
$\mathrm{MgSeO}_{3}$ & 2.87 & {$[39]$} & $\mathrm{MgSeO}_{3} \cdot 6 \mathrm{H}_{2} \mathrm{O}$ & 5.36 & {$[25]$} \\
$\mathrm{Na}_{2} \mathrm{SeO}_{3}$ & 0.02 & {$[37]$} & $\mathrm{Na}_{2} \mathrm{SeO}_{3}$ & 3.51 & {$[40]$} \\
$\mathrm{NaHSeO}_{3}$ & 8.1 & {$[37]$} & $\mathrm{Na}_{2} \mathrm{SeO}_{3} \cdot 5 \mathrm{H}_{2} \mathrm{O}$ & -1.9 & {$[25]$} \\
\hline
\end{tabular}

a Stability constants refer to mass-action equations written with $\mathrm{SeO}_{3}^{2-}$ as the reference species. For instance, $\log K$ for $\mathrm{NaHSeO}_{3}$ corresponds to $\mathrm{Na}^{+}+\mathrm{H}^{+}+\mathrm{SeO}_{3}^{2-}=\mathrm{NaHSeO}_{3}$.

${ }^{\mathrm{b}}$ Mean of four values.

${ }^{c}$ Mean of three values.

Oy, Turku, Finland) was used to measure ${ }^{75} \mathrm{Se}$ activities. The activity of the lower membrane was subtracted from the activity of the upper one to account for $\mathrm{Se}(\mathrm{IV})$ adsorption on filter membranes.

Experiments were performed without the use of $\mathrm{pH}$ buffers. A minimum of three replicates was used for each experimental condition. Uptake results were normalized for the total algal surface area (the surface area of a single cell in exponential phase is $\sim 70 \mu \mathrm{m}^{2}$ ).

\section{Speciation modeling}

The J-Chess speciation program (Armines, Fontainebleau, France) was used to simulate Se(IV) speciation in the exposure solutions. The thermodynamic data were based on a compilation by Denison [23], mainly from the databases from the Organisation for Economic Co-operation and DevelopmentNuclear Energy Agency [24], the National Institute of Standards and Technology [25], and the International Union of Pure and Applied Chemistry [26], but also from a number of other published values critically selected from the literature. The selenium formation constant $(K)$ and solubility product constant $\left(K_{\mathrm{sp}}\right)$ used, given at zero ionic strength and $25^{\circ} \mathrm{C}$, are listed in Table 2.

All calculations were constrained to a fixed-input $\mathrm{pH}$ for each exposure medium at equilibrium with the atmosphere (partial pressure of carbon dioxide $\left[p \mathrm{CO}_{2}\right]=3.16 \times 10^{-4} \mathrm{~atm}$ ) and a fixed $\mathrm{Se}(\mathrm{IV})$ concentration.

\section{Characterization of transport}

The first series of experiments was designed to study the dependence of both adsorption and absorption on exposure time and ambient $\mathrm{Se}(\mathrm{IV})$ concentration. Initial experiments were performed to determine the uptake rate in conditions under which it was expected to be maximal. Because selenium absorption could be inhibited by sulfate $[6,16,27]$ or phosphate [16,18-20,28], the exposures were performed in the absence of those nutrients. Therefore, the exposure medium used was a simplified culture medium, without sulfate, phosphate, or trace metals. The corresponding medium ionic strength was approximately $19.4 \mathrm{mEq} / \mathrm{L}$, similar to the ionic strength of the standard culture medium $(\sim 20 \mathrm{mEq} / \mathrm{L})$, and was not significantly affected by the addition of ${ }^{75} \mathrm{Se}$ stock solutions. Experiments were performed at $\mathrm{pH}$ 7.0.

\section{Uptake kinetics}

The objective of this first experiment was to determine $\mathrm{Se}(\mathrm{IV})$ adsorption levels and initial absorption kinetics. Ad- sorption usually is a rapid phenomenon, whereas absorption is much slower. Hence, on a short time scale, it is expected that adsorption rapidly reaches a steady state, whereas absorption increases linearly with time.

Algae were exposed in the exposure medium described earlier to a total selenium concentration of $50 \mathrm{nM}$, which is close to the waterborne U.S. Environmental Protection Agency national criterion for selenium $(5 \mu \mathrm{g} / \mathrm{L}, \sim 63 \mathrm{nM})$. Selenium adsorption and absorption were measured after exposure periods of $0,15,30,45$, and $60 \mathrm{~min}$. Results were expressed on an algal-surface basis $\left(\mathrm{nmol} / \mathrm{m}^{2}\right)$. They were then normalized with respect to the measured selenium concentrations (nmol/ $\mathrm{m}^{2} / \mathrm{nM}$ ). Finally, the slope of the linear regression with time was used to give an estimation (with a $95 \%$ confidence interval) of the initial conductance $\left(\mathrm{nmol} / \mathrm{m}^{2} / \mathrm{nM} / \mathrm{h}\right)$.

\section{Concentration dependence of Se(IV) uptake}

With a steady-state approach and saturable uptake of a given trace element, membrane transport of an ion $I$ is commonly described by the classical Michaelis-Menten enzymatic model. The uptake flux, $\phi$ (expressed as $\mathrm{nmol} / \mathrm{m}^{2} / \mathrm{h}$ ), is given by the equation $\phi=\left(V_{\mathrm{m}}[I]\right) /\left(K_{\mathrm{m}}+[I]\right)$, where $[I](\mathrm{M})$ is the concentration of the ion in solution, $V_{\mathrm{m}}\left(\mathrm{mol} / \mathrm{m}^{2} / \mathrm{h}\right)$ is the maximum uptake rate, and $K_{\mathrm{m}}(\mathrm{M})$ is the half-saturation constant (concentration of the ion in solution at which the uptake rate is half the maximum uptake rate). Three different ranges of $\mathrm{Se}(\mathrm{IV})$ were investigated: A low concentration range $(0.5-50$ $\mathrm{nM})$, an intermediate range $(0.5 \mathrm{nM}$ to $2.5 \mu \mathrm{M})$, and a high concentration range $(50 \mathrm{nM}$ to $5.5 \mathrm{mM})$. A fixed exposure time of $60 \mathrm{~min}$ was used. Fluxes were calculated at each concentration and log-transformed to achieve homogeneity of variance. Finally, an analysis of variance (ANOVA) completed by lowest-significant-difference (LSD) post-hoc comparisons was performed to test for significant differences between fluxes at different contamination levels.

\section{Effect of varying anion concentrations}

As an oxyanion, there could be competition for transport sites for Se(IV) with sulfate, phosphate, nitrate, or carbonate species; thus, the nutrient content of the medium could directly influence its assimilation by the cells. We therefore tested for the inhibition of $\mathrm{Se}(\mathrm{IV})$ uptake by increasing concentrations of those different potential competitors in solution. Ionic strength was not maintained at a constant level, because counter ions also could have an effect on transport. Addition of nitrate salts notably increased medium ionic strength by more than threefold. However, in the cases of sulfate, phosphate, 
and bicarbonate, the increases were less important (maximum increase in ionic strength of 17,4 , and $13 \%$, respectively). In the culture medium, nutrient concentrations were not changed. Total Se(IV) concentration was $50 \mathrm{nM}$, and cells were exposed for $60 \mathrm{~min}$ at a $\mathrm{pH}$ of 7.0. Nonparametric Kruskal-Wallis rank sum tests were performed to test for any significant effect of increasing concentrations of the different elements.

\section{Inhibition by sulfate, phosphate, and nitrate}

To test for the possible competition of sulfate for Se(IV) accumulation, cells were exposed in a simplified culture medium, without phosphate or trace metals, to increasing concentrations of $\mathrm{SO}_{4}^{2-}(0.08,0.8,8,80$, and $800 \mu \mathrm{M})$, obtained by addition of appropriate volumes of a stock solution. Two series of experiments were performed, the first adding $\mathrm{SO}_{4}^{2-}$ as $\mathrm{K}_{2} \mathrm{SO}_{4}$ and the second adding $\mathrm{SO}_{4}^{2-}$ as $\mathrm{Na}_{2} \mathrm{SO}_{4}$. The ionic strength varied from approximately 19.4 to approximately 22.6 $\mathrm{mEq} / \mathrm{L}$.

To test for the possible competition between Se(IV) and phosphate, cells were exposed in a simplified culture medium, without sulfate or trace metals, to increasing concentrations of $\mathrm{PO}_{4}^{3-}(0,1.37,13.7,54.8$, and $137 \mu \mathrm{M})$, added as a mixture of $\mathrm{KH}_{2} \mathrm{PO}_{4}$ and $\mathrm{K}_{2} \mathrm{HPO}_{4}$ to maintain a constant $\mathrm{pH}$ (molar ratio, $\sim 2: 5$ and $3: 5$, respectively). The ionic strength varied from approximately 19.4 to approximately $20.2 \mathrm{mEq} / \mathrm{L}$.

Finally, to test for the possible competition between Se(IV) and nitrate, cells were similarly exposed in a simplified culture medium, without sulfate, phosphate, or trace metals, to increasing concentrations of $\mathrm{NO}_{3}^{-}(0,0.030,0.30,3.0,10$, and 30 $\mathrm{mM}$ ), added as a mixture of $\mathrm{KNO}_{3}$ and $\mathrm{Mg}\left(\mathrm{NO}_{3}\right)_{2} \cdot 6 \mathrm{H}_{2} \mathrm{O}$ (molar ratio, $\sim 1: 2$ and $1: 2$, respectively). The ionic strength varied from approximately 15.5 to approximately $55.5 \mathrm{mEq} / \mathrm{L}$.

\section{Inhibition by carbonate species}

At equilibrium with the atmosphere $\left(\mathrm{CO}_{2}=3.16 \times 10^{-4}\right.$ atm), the concentration of dissolved inorganic carbon in an aqueous medium is $\mathrm{pH}$-dependent. To test the effect of increasing concentrations of dissolved inorganic carbon at a fixed $\mathrm{pH}$, we performed the exposure in closed systems at different $p \mathrm{CO}_{2}$ values. The solutions were prepared by adding appropriate volumes of standard solutions of $\mathrm{NaOH}$ and $\mathrm{NaHCO}_{3}$ to the Erlenmeyer flasks immediately before the exposure of algae and then rapidly sealing them to prevent $\mathrm{CO}_{2}$ outgassing. The final solutions were designed to have the desired $\mathrm{pH}$ and total dissolved inorganic carbon concentrations in equilibrium with the gas volume of the sealed tubes, without the need for additional $\mathrm{pH}$ buffers. The exposure medium was a simplified culture medium, without sulfate, phosphate, or trace metals but with increasing $\mathrm{HCO}_{3}^{-}$concentrations of 50, 250, 500, $1,000,2,500$, and 5,000 $\mu \mathrm{M}$, corresponding to calculated $p \mathrm{CO}_{2}$ values of 1-, 5-, 10-, 20-, 50-, and 100-fold the normal atmospheric $p \mathrm{CO}_{2}$, respectively. The ionic strength varied from approximately 19.4 to approximately $21.9 \mathrm{mEq} / \mathrm{L}$. The $\mathrm{pH}$ and dissolved inorganic carbon concentrations were measured in samples of each medium immediately before and after the exposure to verify the effectiveness of our approach. Dissolved inorganic carbon concentrations were measured using a total organic carbon analyzer (Shimazu, Kyoto, Japan).

\section{Links between $\mathrm{Se}(I V)$ speciation and transport: Effect of $p H$}

Using simulations performed with J-Chess, we estimated the theoretical influence of $\mathrm{pH}$ on the distribution of the dif-

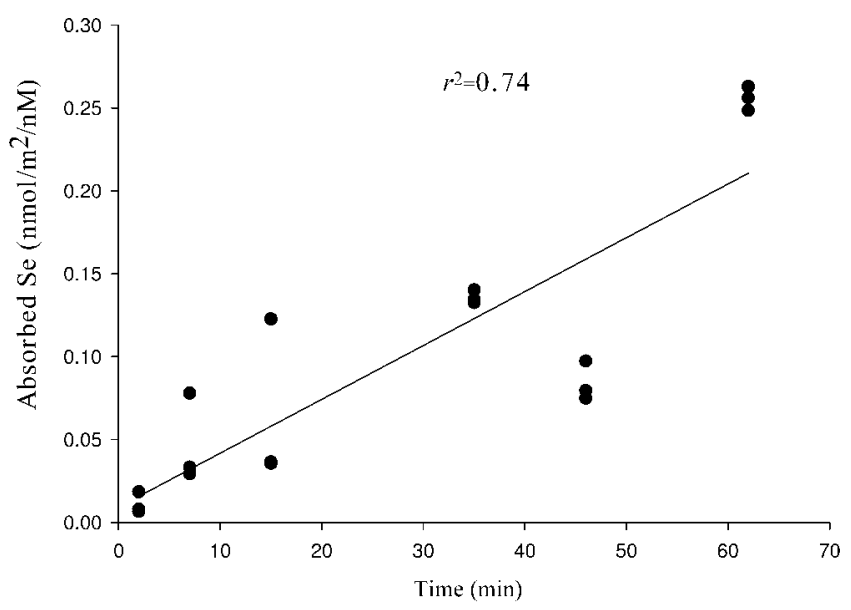

Fig. 1. Selenium uptake kinetics by Chlamydomonas reinhardtii at a constant selenite (Se(IV)) concentration $(50 \mathrm{nM})$ in the absence of sulfate and phosphate and at $\mathrm{pH}$ 7. Three replicates per sampling time were used. Absorbed selenium is expressed on the basis of the algal surface $\left(\mathrm{nmol} / \mathrm{m}^{2} / \mathrm{nM}\right)$.

ferent $\mathrm{Se}(\mathrm{IV})$ species in our exposure medium. Because $\mathrm{pH}$ had a strong influence on the speciation of Se(IV), we used this parameter to investigate links between speciation and uptake. We exposed cells in a simplified culture medium, without sulfate, phosphate, or trace metals, to varying $\mathrm{pH}$ values of 5.0, 6.0, 6.5, 7.0, 7.5, and 8.0, adjusted by additions of either $\mathrm{HNO}_{3}$ or $\mathrm{KOH}$. Total Se(IV) concentration was $50 \mathrm{nM}$, and cells were exposed for $60 \mathrm{~min}$. The $\mathrm{pH}$ was measured at both the beginning and the end of the experiments. Results were analyzed by the nonparametric Kruskal-Wallis rank sum test for any significant effect of increasing $\mathrm{pH}$.

The Statistica ${ }^{\circledR} 6.1$ software package (StatSoft, Tulsa, OK, USA) was used to perform all statistical analyses.

\section{RESULTS AND DISCUSSION}

\section{Adsorption on algal cells}

Total Se(IV) uptake was not significantly different from intracellular uptake for any experimental condition, indicating that the adsorbed fraction was negligible compared to the absorbed one. In the literature, contrasting results concerning the importance of selenium adsorption to the cell surface can be found. Previous use of live and dead cells has given opposite trends $[8,14,15]$. Our own observations are coherent with the general tenet that negatively charged functional groups at the cell surface are more likely to repulse than to attract oxyanions, thus limiting adsorption.

\section{Uptake kinetics}

Results from the kinetic experiments showed an increase in intracellular $\mathrm{Se}(\mathrm{IV})$ concentrations over the 60-min exposure periods (Fig. 1). The calculated absorption conductance, given by the slope of the linear regression, was $0.19 \mathrm{nmol} / \mathrm{m}^{2} /$ $\mathrm{nM} / \mathrm{h}$, with a $95 \%$ confidence interval of between 0.13 and $0.26 \mathrm{nmol} / \mathrm{m}^{2} / \mathrm{nM} / \mathrm{h}$. The intercept of the linear regression was not significantly different from zero $(p>0.5)$, indicating the absence of residual surface-bound Se(IV). The measured conductance was consistent with the conductance estimated by Riedel and Sanders [16] for the same alga $\left(\sim 0.27 \mathrm{nmol} / \mathrm{m}^{2} /\right.$ $\mathrm{nM} / \mathrm{h})$. This value is close to the conductance measured in similar experimental conditions for chloride $\left(0.33 \mathrm{nmol} / \mathrm{m}^{2} /\right.$ $\mathrm{nM} / \mathrm{h}$ [29]). Because of the negative membrane potential, the 

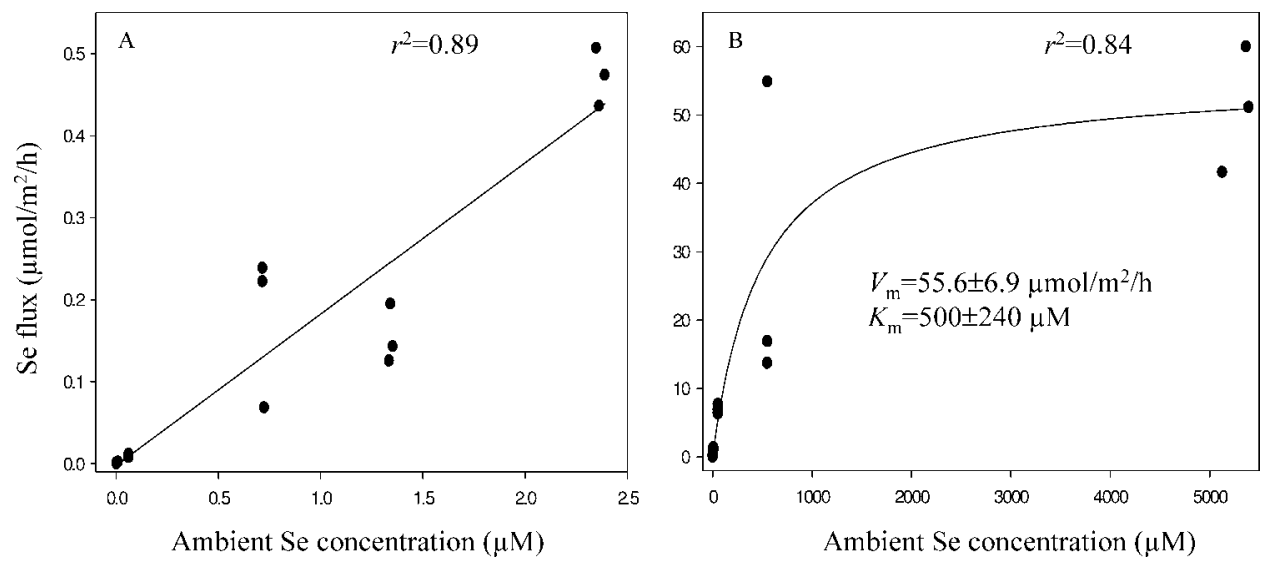

Fig. 2. Concentration dependence of selenium uptake by Chlamydomonas reinhardtii after $1 \mathrm{~h}$ of exposure in the absence of sulfate and phosphate and at $\mathrm{pH}$ 7. (A) Intermediate selenite (Se(IV)) exposure concentrations and linear regression. (B) High Se(IV) exposure concentrations and Michaelis-Menten fit. Three replicates per concentration were used.

transport of anions into the cell is unlikely to occur by simple passive diffusion down the electrochemical gradient through ionic channels, as can be the case for some cations. For instance, anions, such as phosphate and sulfate, are cotransported into the cell by a sodium symport mechanism. More generally, transport of anions is ensured by active anion/proton symport mechanisms or anion/anion antiport mechanisms that are energetically costly. The measured conductance of $\mathrm{Se}$ (IV) may be explained by the existence of a specific transport system for Se(IV). Because selenium has been demonstrated to be essential for many plants and algae, including Chlamydomonas sp. [1], selenium-specific transporters could exist. Another explanation could be the "accidental" transport of Se(IV) through nonspecific transporters by ion mimicry.

\section{Concentration dependence of $\mathrm{Se}(I V)$ uptake}

Transport of Se(IV) was characterized by three successive experiments (Figs. 2 and 3). For intermediate Se(IV) ambient concentrations up to $2.4 \mu \mathrm{M}$, results showed a linear intracellular uptake, with no saturation pattern (Fig. 2A). The corresponding estimated conductance (slope of the linear regression between uptake and measured ambient concentration) was $0.2 \mathrm{nmol} / \mathrm{m}^{2} / \mathrm{nM} / \mathrm{h}$, with a $95 \%$ confidence interval ranging

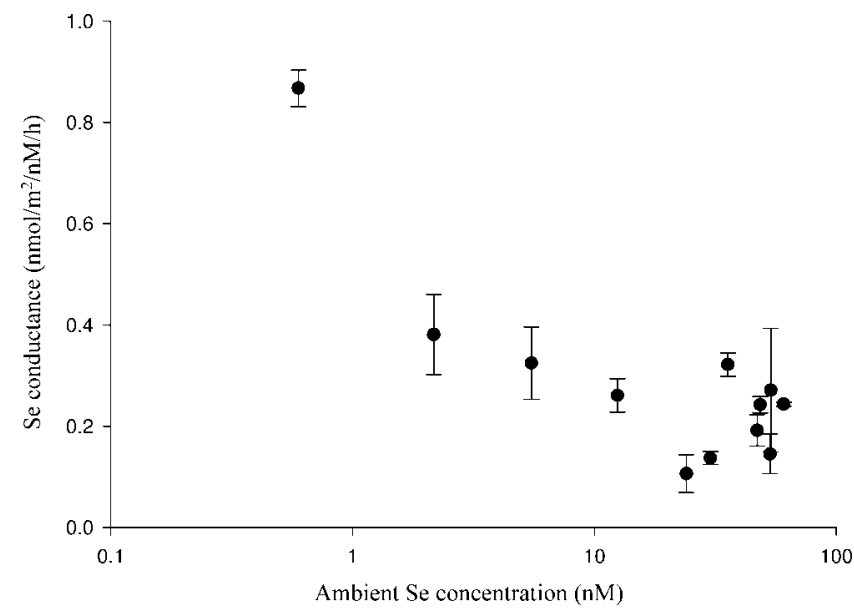

Fig. 3. Selenium conductances in Chlamydomonas reinhardtii estimated from 1-h exposure periods to low selenite (Se(IV)) ambient concentrations at $\mathrm{pH} 7$ without sulfate or phosphate. Error bars represent standard deviations from the average of three replicates. between 0.15 and $0.22 \mathrm{nmol} / \mathrm{m}^{2} / \mathrm{nM} / \mathrm{h}$, which is in agreement with the conductance estimated during the uptake kinetics experiment. Fluxes calculated for each exposure concentration are reported in Table 3. Results of the ANOVA showed no difference between fluxes in the measured $6.0 \mathrm{nM}$ to $2.4 \mu \mathrm{M}$ range (ANOVA and LSD post-hoc test, $p>0.05$ ). The flux observed at the lowest concentration $(0.5 \mathrm{nM})$ was significantly higher than that seen for all other fluxes (approximately one order of magnitude; ANOVA and LSD post-hoc test, $p<$ 0.0005), suggesting that a saturation of involved transporters could occur at very low concentrations.

Results from a second series of experiments using concentrations ranging from $60 \mathrm{nM}$ to $5.3 \mathrm{mM}$ showed a saturation of absorption in the micromolar range (Fig. 2B), with conductances decreasing significantly with increasing $\mathrm{Se}(\mathrm{IV})$ concentrations (Table 2). Results of the ANOVA showed significant differences for each treatment against one another (ANOVA and LSD post-hoc test, $p<0.0005$ ), except for the 500 $\mathrm{nM}$ treatment against the $60 \mathrm{nM}$ treatment $(p>0.05)$. The fit of a Michaelis-Menten curve to concentration uptake data (Fig. 2B) $\left(r^{2}=0.84, p<0.0001\right)$ allowed the estimation of Michaelis-Menten constants. The maximum uptake rate $\left(V_{\mathrm{m}}\right)$ was computed to be $55.6 \pm 6.9 \mu \mathrm{mol} / \mathrm{m}^{2} / \mathrm{h}$; however, data were too variable to give an accurate estimation of the $K_{\mathrm{m}}$ value $(500 \pm 240 \mu \mathrm{M})$. Note that $\mathrm{Se}(\mathrm{IV})$ aqueous speciation modeling indicates that our experimental medium becomes slightly oversaturated with respect to both calcium and magnesium $\mathrm{Se}(\mathrm{IV})$ mineral phases at the highest concentration tested (mea-

Table 3. Measured ambient selenite concentrations and corresponding calculated inner fluxes in Chlamydomonas reinhardtii (mean \pm standard error, $n=3)^{\mathrm{a}}$

\begin{tabular}{ccccc}
\hline \multicolumn{2}{c}{ Intermediate level } & & \multicolumn{2}{c}{ High level } \\
\cline { 1 - 2 } \cline { 5 - 5 } $\begin{array}{c}\text { Exposure } \\
\text { concentration }\end{array}$ & $\begin{array}{c}\text { Conductance } \\
\left(\mathrm{nmol} / \mathrm{m}^{2} / \mathrm{nM} / \mathrm{h}\right)\end{array}$ & $\begin{array}{c}\text { Exposure } \\
\text { concentration }\end{array}$ & $\begin{array}{c}\text { Conductance } \\
\left(\mathrm{nmol} / \mathrm{m}^{2} / \mathrm{nM} / \mathrm{h}\right)\end{array}$ \\
\hline $0.5 \pm 0.01 \mathrm{nM}$ & $2 \pm 0.6$ & & $60 \pm 0.05 \mathrm{nM}$ & $0.43 \pm 0.007$ \\
$6 \pm 0.02 \mathrm{nM}$ & $0.3 \pm 0.03$ & $500 \pm 3 \mathrm{nM}$ & $0.48 \pm 0.04$ \\
$60 \pm 0.4 \mathrm{nM}$ & $0.17 \pm 0.02$ & $5 \pm 0.02 \mu \mathrm{M}$ & $0.22 \pm 0.01$ \\
$700 \pm 2 \mathrm{nM}$ & $0.25 \pm 0.08$ & $50 \pm 0.2 \mu \mathrm{M}$ & $0.13 \pm 0.007$ \\
$1.3 \pm 0.006 \mu \mathrm{M}$ & $0.11 \pm 0.01$ & $550 \pm 0.2 \mu \mathrm{M}$ & $0.05 \pm 0.02$ \\
$2.4 \pm 0.01 \mu \mathrm{M}$ & $0.2 \pm 0.009$ & $5.3 \pm 0.08 \mathrm{mM}$ & $0.01 \pm 0.001$ \\
\hline
\end{tabular}



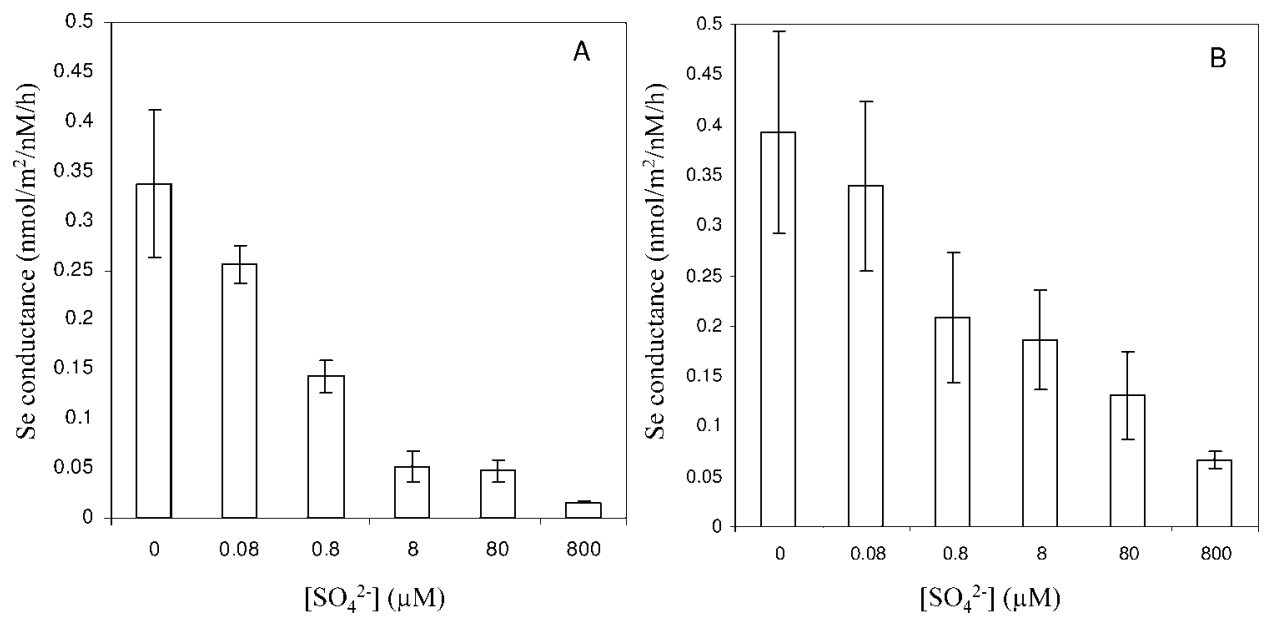

Fig. 4. Selenium conductances in Chlamydomonas reinhardtii estimated from 1-h exposure periods to a constant selenite (Se(IV)) ambient concentration $(50 \mathrm{nM})$ at $\mathrm{pH} 7$ without phosphate but with increasing sulfate concentrations added either as $\mathrm{K}_{2} \mathrm{SO}_{4}(\mathbf{A})$ or $\mathrm{Na}_{2} \mathrm{SO}_{4}(\mathbf{B})$. Error bars represent standard deviations from the average of three replicates.

sured total $\mathrm{Se}(\mathrm{IV}), 5.3 \mathrm{mM})$. However, even if the thermodynamic equilibrium is reached, which is uncertain considering the expected slow kinetics of mineral formation, the calculated remaining dissolved concentration of $\mathrm{Se}(\mathrm{IV})$ is approximately $3 \mathrm{mM}$.

Finally, in an attempt to characterize Se(IV) transport at low concentrations $(0.5-50 \mathrm{nM})$, we found that conductances decreased rapidly with increasing $\mathrm{Se}(\mathrm{IV})$ concentrations and then stabilized around a value of $0.2 \mathrm{nmol} / \mathrm{m}^{2} / \mathrm{nM} / \mathrm{h}$ (Fig. 3), which supports our previous observation at $0.5 \mathrm{nM} \mathrm{Se}(\mathrm{IV})$ (Table 3). This suggests the presence of few very-high-affinity transporters that become rapidly saturated at subnanomolar concentrations. The conductance was significantly higher at $0.5 \mathrm{nM}$ compared to that estimated at any other concentration (Fig. 3) (ANOVA and post-hoc LSD test, $p<0.005$ ).

Many studies relating $\mathrm{Se}(\mathrm{IV})$ uptake to $\mathrm{Se}(\mathrm{IV})$ concentration have suggested a linear relationship over a given concentration range [14,21]. Our results suggest that absorption follows two successive Michaelis-Menten kinetics, one with low constants and one with high constants, so that the relation appears to be linear in a broad range of intermediate concen-

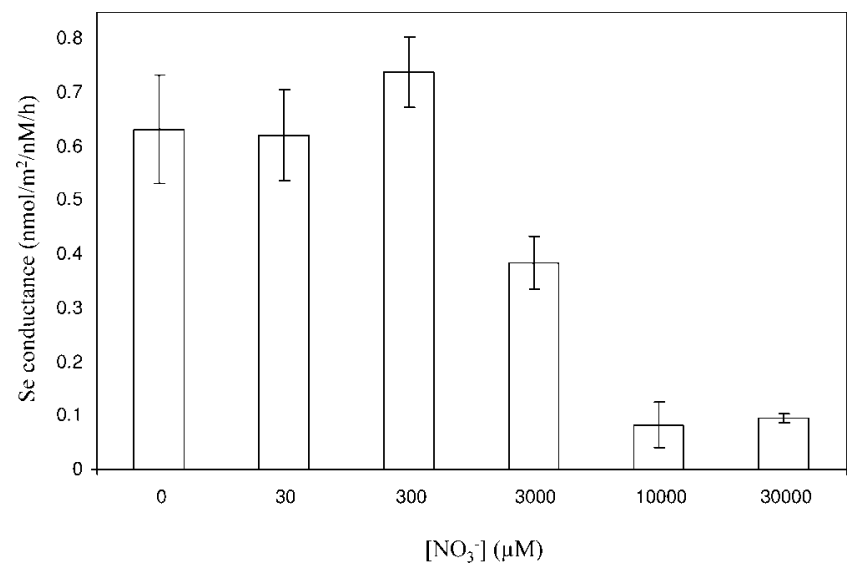

Fig. 5. Selenium conductances in Chlamydomonas reinhardtii estimated from 1-h exposure periods to a constant selenite (Se(IV)) ambient concentration $(50 \mathrm{nM})$ in the absence of sulfate and phosphate but with increasing nitrate concentrations added as $\mathrm{KNO}_{3}$ at $\mathrm{pH} 7$. Error bars represent standard deviations from the average of three replicates. trations, including those ranges used by Boisson et al. [8] as well as Riedel and Sanders [16] - that is, from approximately 1.3 to $13 \mu \mathrm{M}$ and approximately 12 to $650 \mathrm{nM}$, respectively.

Based on these results, we suggest that $\mathrm{Se}$ (IV) transport is biphasic. In other words, transport occurs by two different mechanisms, depending on the ambient concentration.

The higher conductances found at low concentrations suggest the presence of a high-affinity transport system at low $\mathrm{Se}(\mathrm{IV})$ levels that is rapidly saturated, which in turn suggests that the transporters involved are scarce. The saturation of a high-affinity transport system at low concentrations $(\sim \mathrm{nM})$ is supported by previous results from Baines and Fisher [30], who showed a great variation of cellular selenium concentration between 0.01 and $0.1 \mathrm{nM}$ of added $\mathrm{Se}(\mathrm{IV})$ and stabilization at greater than $0.15 \mathrm{nM}$ in 13 of the 14 coastal and estuarine algal species tested. Given the essentiality of selenium for $C$. reinhardtii, the existence of a specific, constitutive seleniumtransport system would not be surprising.

At higher concentrations ( $>1 \mathrm{nM}), \mathrm{Se}(\mathrm{IV})$ uptake is linear up to micromolar levels. Increasing the ambient selenium concentrations further showed that this second mechanism also saturates, which strongly suggests a mediated (facilitated) ion transport. However, concentrations needed to saturate these ion transporters are high $(\sim \mathrm{mM})$, with high $K_{\mathrm{m}}$ and $V_{\mathrm{m}}$ values, suggesting an uptake through numerous and nonspecific transporters. Previous experiments have shown that selenium becomes toxic at such high concentrations $(\sim \mu \mathrm{M})[9,10]$, modifying algal metabolism and, thus, probably also uptake rates; however, such toxic effects might not appear in short-term experiments, during which only initial uptake rates are measured. These numerous and nonspecific transporters could be those used by sulfate, phosphate, nitrate, or carbonate species. This would be consistent with the idea that contaminants forming oxyanions could be transported through the numerous and poorly selective channels used by those anions [17].

\section{Effect of varying anion concentrations}

Selenite uptake was significantly inhibited by increasing concentrations of sulfate (whether sulfate was added as $\mathrm{K}_{2} \mathrm{SO}_{4}$ or as $\mathrm{Na}_{2} \mathrm{SO}_{4} ; p=0.014$ and $p=0.045$, respectively) (Fig. 4 ) and nitrate $(p=0.01)$ (Fig. 5) but was independent of phosphate and dissolved inorganic carbon levels $(p>0.05)$ 

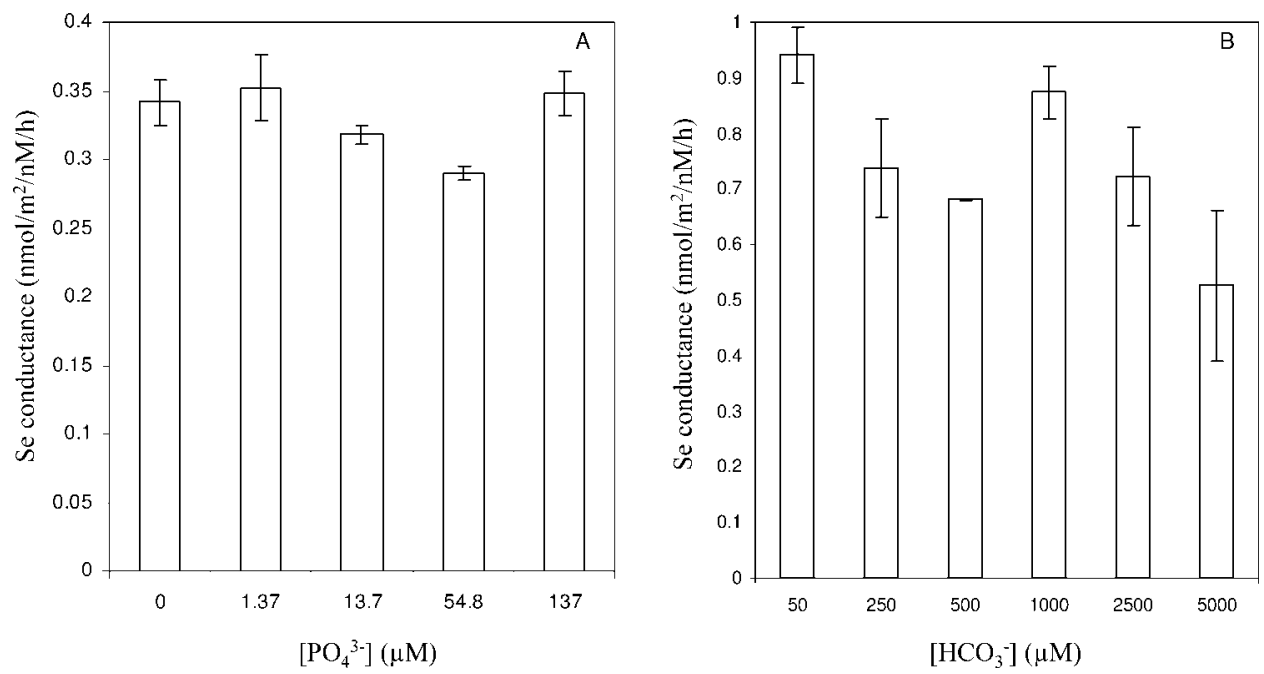

Fig. 6. Selenium conductances in Chlamydomonas reinhardtii estimated from 1-h exposure periods to a constant selenite (Se(IV)) ambient concentration $(50 \mathrm{nM})$ at $\mathrm{pH} 7(\mathbf{A})$ without sulfate but with increasing phosphate concentrations added as a mixture of $\mathrm{KH}_{2} \mathrm{PO}_{4}$ and $\mathrm{K}_{2} \mathrm{HPO}_{4}$ and (B) without sulfate and phosphate but with increasing carbonate concentrations added as $\mathrm{NaHCO}_{3}$ in closed Erlenmeyer flasks. Error bars represent standard deviations from the average of three measurements.

(Fig. 6). Based on thermodynamic modeling, Se(IV) speciation remained virtually constant throughout all of these experiments. Hence, the effects observed are not expected to be influenced by changes to Se(IV) speciation.

Addition of sulfate, phosphate, and bicarbonate salts increased the ionic strength of the medium very slightly, whereas addition of the nitrate salts increased it notably. Among other factors, variation of the ionic strength involves modification of the surface charge potential of the biological membrane. However, it is expected that increasing ionic strength tends to enhance anion uptake because of the tendency for charge neutralization of the negatively charged interface. The inhibitions observed thus are likely to be caused by competition between $\mathrm{Se}(\mathrm{IV})$ and the tested anions.

A number of complex interacting factors influence element accumulation by phytoplankton. Few studies have considered the influence of major nutrients on metal uptake; the nutritional status of the cells has effects on assimilatory pathways and can influence uptake through several mechanisms. Under nutrient limitation, weakened algae can be more sensitive to toxic metals [31]. The inhibition of cellular growth rate induced by metal deficiency also can lower the biodilution rate, thus increasing cellular metal concentration [21]. On the contrary, nutrient enrichment can increase metal uptake in correlation with an enhanced metabolism [28]. In the case of anionic contaminants, the effect of nutrients is even more complicated because of the possible direct competition for binding to membrane-transport sites if common transport systems are involved [17]. Studies investigating the effect of dissolved inorganic carbon on metal uptake are scarce, probably because of the experimental difficulty in maintaining a constant $\mathrm{pH}$ with varying dissolved inorganic carbon concentrations without using buffers. Carbonate species were shown to inhibit $\mathrm{TcO}_{4}^{-}$uptake by several cyanobacterial species, probably because of a competition for transport sites [32]. Such competition did not occur in our experiments in the case of $\mathrm{Se}(\mathrm{IV})$ and $C$. reinhardtii. An antagonism between Se(IV) and phosphate was found for several freshwater algae, including $C$. reinhardtii $[16,19,20]$, and also in marine species [18]. The authors proposed that selenium might be transported as a phosphate analog when ambient phosphate concentrations are low. However, Se(IV) absorption was not inhibited by increasing phosphate concentrations in our experiments. The difference observed could be related to the shorter exposure periods used and to the fact that our algae were not acclimated to a phosphate-depleted medium. The phosphate-limited cells usually are quite sensitive to metals: Phosphate depletion may influence metal exclusion [28]. These processes might occur on longer time scales than those we examined, for which only the initial transport rates were studied.

As group VI elements, selenium and sulfur share many chemical properties. Selenium has been shown to compete with sulfur for assimilation pathways in several organisms $[6,27,33,34]$. Several studies of algae, bacteria, and other organisms have shown an inhibition of $\mathrm{Se}(\mathrm{VI})$ uptake by sulfate $[16,27,34]$, and one study of bacteria has shown an inhibition of both $\mathrm{Se}(\mathrm{VI})$ and $\mathrm{Se}(\mathrm{IV})$ by sulfite [35]. To our knowledge, the present study is the first report of an inhibitory effect of sulfate on $\mathrm{Se}(\mathrm{IV})$ uptake in algae. Moreover, the inhibition occurs at sulfate concentrations in the range of those that can be found in the environment. Given the chemical similarity between selenium and sulfur, the inhibition induced by sulfate is likely to be caused by a direct competition for transport sites. The low affinity of Se(IV) for the transporters involved is proved by the high $K_{\mathrm{m}}$ value $(500 \mu \mathrm{M})$. Given the pattern of the inhibition by sulfate (less than twofold decrease of Se(IV) absorption for a 10-fold increase of sulfate concentrations) and the fact that sulfate only was not sufficient to inhibit $\mathrm{Se}(\mathrm{IV})$ uptake completely (a constant influx of $\mathrm{Se}$ (IV) [exposure concentration, $50 \mathrm{nM}$ ] was observed at sulfate concentrations $>800 \mu \mathrm{M}$ ), the affinity of sulfate for the transporters is not expected to be much higher than that of Se(IV). Sulfate has been shown to be transported via biphasic transporters: One of high affinity, and one of low affinity. Transporters shared by $\mathrm{Se}(\mathrm{IV})$ and sulfate may be the low-affinity transporters of sulfate.

A similar antagonism has been shown between sulfate and two other oxyanions, molybdate and chromate. This was related to uptake by the cells' sulfate transport system [17]. Thus, 

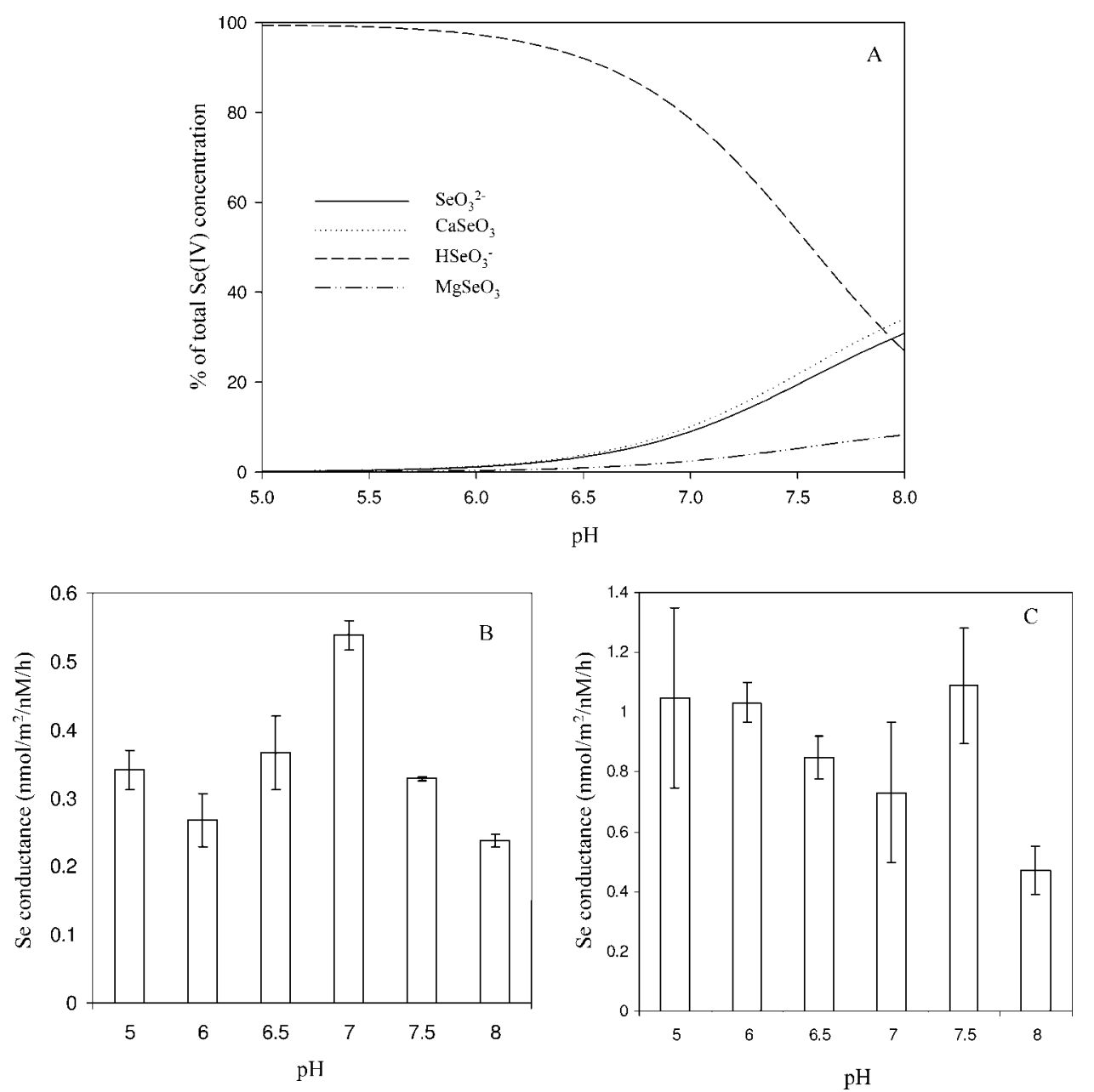

Fig. 7. (A) Results of J-Chess thermodynamic chemical modeling on the influence of $\mathrm{pH}$ on selenite (SeIV)) aqueous speciation. Calculations were performed using a total selenium concentration of $50 \mathrm{nM}$ and simplified culture medium without sulfate, phosphate, or trace metals. (B) Selenium conductances in Chlamydomonas reinhardtii estimated for a 1-h exposure period to a constant Se(IV) ambient concentration (50 nM) without sulfate or phosphate and for $\mathrm{pH}$ ranging from 5.0 to 8.0. (C) Selenium conductances estimated for a 1-h exposure period to a constant $\mathrm{Se}(\mathrm{IV})$ concentration $(50 \mathrm{nM})$ without sulfate or phosphate and for $\mathrm{pH}$ ranging from 5.0 to 8.0. Algae were preexposed for $1 \mathrm{~h}$ at the given $\mathrm{pH}$ in the exposure medium before Se(IV) exposure. Error bars represent standard deviations from the average of three replicates.

uptake of oxyanions via the low-affinity transport system of sulfate could be a general phenomenon.

Major differences between freshwater and marine algae in their metal accumulation exist in their response to different nitrogen conditions, presumably linked to the fact that nitrogen is the limiting nutrient for marine phytoplankton, whereas freshwater systems generally are limited by phosphate. The effect of nitrogen enrichment on metal uptake in freshwater green algae is still not clear. Studies dealing with the influence of nitrate on $\mathrm{Se}(\mathrm{IV})$ uptake have shown, variously, an inhibition [19], an enhancement [28], or an absence of effect $[16,18]$ on $\mathrm{Se}(\mathrm{IV})$ accumulation with increasing nitrate concentrations. In our experiments, Se(IV) was inhibited significantly by nitrate. However, the concentrations needed to observe an inhibition were high $(\sim \mathrm{mM})$ and, thus, were not environmentally realistic. The inhibition could be linked either to a direct competition for transport sites or to an indirect effect on the activity of the transporter systems. Uptake of the oxyanion pertechnetate via a nitrate transport system has been shown [36], and uptake of oxyanions via the low-affinity transport system of nitrate could be a general phenomenon. Further experiments would be necessary to understand which mech- anism is responsible for inhibition of $\mathrm{Se}(\mathrm{IV})$ transport by increasing nitrate concentration.

\section{Links between $\mathrm{Se}(\mathrm{IV})$ speciation and transport: Effects of $\mathrm{pH}$}

The predicted changes to $\mathrm{Se}(\mathrm{IV})$ aqueous speciation as a function of $\mathrm{pH}$ are shown in Figure 7A. Major Se(IV) species in the exposure medium were $\mathrm{HSeO}_{3}^{-}, \mathrm{SeO}_{3}^{2-}, \mathrm{CaSeO}_{3}$, and $\mathrm{MgSeO}_{3}$. At low $\mathrm{pH}$ values, $\mathrm{HSeO}_{3}^{-}$was the dominant species, but as the $\mathrm{pH}$ increases, the concentrations of $\mathrm{SeO}_{3}^{2-}, \mathrm{CaSeO}_{3}$, and $\mathrm{MgSeO}_{3}$ became significant. Selenite uptake was significantly different $(p<0.05)$ across the range of $\mathrm{pH}$ values tested, but with no clear trend (Fig. 7B). This experiment was repeated using cells that were preacclimated to the experimental $\mathrm{pH}$ values, and the results again varied significantly, but with no apparent meaningful pattern (Fig. 7C).

It is well known that the $\mathrm{pH}$ of the medium can influence uptake of ions in several ways, including the modification of the overall algal surface charge, the speciation of ions in solution, and the properties of membrane transport mechanisms. The $\mathrm{pH}$ also modifies dissolved inorganic carbon concentrations of the media in open systems, but because we did not 
find any effect of dissolved inorganic carbon concentration on $\mathrm{Se}(\mathrm{IV})$ uptake, we neither controlled nor measured dissolved inorganic carbon concentrations in our exposure media. An increased uptake of $\mathrm{Se}(\mathrm{IV})$ at low $\mathrm{pH}$ values might be expected as a result of protonation of the anionic surface groups of the membrane interface and the consequent reduction to the negative surface charge potential, but this was not evidenced. The predicted changes to the concentrations of the different Se(IV) species did not translate to a clear increase or decrease of accumulation, as would be expected if accumulation was linked to a particular species. We know of only one other study in which the influence of $\mathrm{pH}$ on $\mathrm{Se}(\mathrm{IV})$ accumulation was examined. It reported an increased $\mathrm{Se}(\mathrm{IV})$ uptake at low $\mathrm{pH}$ values $(\mathrm{pH} \mathrm{5)}$ compared to that at higher $\mathrm{pH}$ values $(\mathrm{pH}>6)$ [16]. The difference observed may be linked to the fact that those authors used longer exposure periods, higher ambient $\mathrm{Se}(\mathrm{IV})$ concentrations, and buffers to maintain a constant $\mathrm{pH}$. Our results suggest that the effect of Se(IV) speciation on its bioavailability is less than other effects of $\mathrm{pH}$ on the physiology or metabolism of the alga. Poor selectivity of the involved transport systems with a consequent lack of discrimination between the different $\mathrm{Se}$ (IV) species could explain the absence of an effect of $\mathrm{pH}$ on $\mathrm{Se}(\mathrm{IV})$ bioavailability. Results could, however, be different at lower ambient Se(IV) concentrations, at which a specific transport may occur.

Note that the measured conductances varied between the different experimental conditions without affecting uptake trends between the different experiments or intraexperimental consistency. For example, compared to other experiments, in which the conductance was approximately $0.2 \mathrm{nmol} / \mathrm{m}^{2} / \mathrm{nM} / \mathrm{h}$, the measured conductance was approximately fourfold higher in the experiment investigating the influence of dissolved inorganic carbon concentration (Fig. 6B) and in the experiment studying the influence of $\mathrm{pH}$ with preacclimation to the given $\mathrm{pH}$ (Fig. 7C). This has been observed previously and may be explained by an intergenerational variability [30].

\section{CONCLUSION}

Based on the present results and those available in the literature, it seems quite plausible that the transport of Se(IV) involves two mechanisms: A specific, high-affinity, but rapidly saturated transport system may be responsible for accumulation at low concentrations $(<\mathrm{nM})$, and a less specific one when concentrations increase. The latter could be ensured by the numerous and poorly selective channels used by anionic macronutrients, an idea that is supported by the significant inhibition of $\mathrm{Se}(\mathrm{IV})$ uptake by sulfate and nitrate, and the apparent insensitivity of bioavailability to changes in chemical speciation. Hence, the inhibition effects observed might vary greatly, depending on the ambient Se(IV) concentration. Conductances are, indeed, higher at environmentally relevant levels of $\mathrm{Se}(\mathrm{IV})$ (in the $<\mathrm{nM}$ range), and uptake may be influenced by parameters other than those we studied. Moreover, the cycling of selenium in realistic environmental conditions can be complicated considerably by the interaction with major nutrients, more particularly sulfate. For example, large concentrations of sulfate usually encountered in mining effluents could mitigate the impact of selenium on phytoplankton. On the other hand, bioconcentration factors determined under laboratory conditions, which typically use high nutrient concentrations, may underestimate the accumulation and potential toxicity of selenium to phytoplankton.
Acknowledgement-We thank L. Février for her thorough review of the selenium thermodynamic data literature and useful help in geochemical modeling. We are grateful to M. Morello for his technical assistance with liquid scintillation measurements and to F.H. Denison and R. Gilbin for numerous discussions on the subject and useful help, especially in the design of the carbonate experiment. This paper was checked for English by a native speaker, F.H. Denison. The present study was part of the "ENVIRHOM" (radioprotection from environment to man) research program supported by the Institute for Radioprotection and Nuclear Safety.

\section{REFERENCES}

1. Novoselov SV, Rao M, Onoshko NV, Zhi H, Kryukov GV, Xiang Y, Weeks DP, Hatfield DL, Gladyshev VN. 2002. Selenoproteins and selenocysteine insertion system in the model plant cell system, Chlamydomonas reinhardtii. EMBO J 21:3681-3693.

2. Yokota A, Shigeoka S, Onishi T, Kitaoka S. 1988. Selenium as inducer of glutathione peroxidase in low- $\mathrm{CO}_{2}$-grown Chlamydomonas reinhardtii. Plant Physiol 86:649-651.

3. Conde JE, Sanz Alaejos M. 1997. Selenium concentrations in natural and environmental waters. Chem Rev 97:1979-2003.

4. Fan TWM, Teh SJ, Hinton DE, Higashi RM. 2002. Selenium biotransformation into proteinaceous forms by food web organisms of selenium-laden drainage waters in California. Aquat Toxicol 57:65-84.

5. Lemly AD. 2004. Aquatic selenium pollution is a global environmental safety issue. Ecotoxicol Environ Saf 59:44-56.

6. Wheeler AE, Zingaro RA, Irgolic K. 1982. The effect of selenate, selenite, and sulfate on the growth of six unicellular marine algae. J Exp Mar Biol Ecol 57:181-194.

7. Kiffney P, Knight A. 1990. The toxicity and bioaccumulation of selenate, selenite, and seleno-L-methionine in the cyanobacterium Anabaena flos-aquae. Arch Environ Contam Toxicol 19:488494.

8. Boisson F, Gnassia-Barelli M, Romeo M. 1995. Toxicity and accumulation of selenite and selenate in the unicellular marine alga Cricosphaera elongata. Arch Environ Contam Toxicol 28:487493.

9. Morlon H, Fortin C, Floriani M, Adam C, Garnier-Laplace J, Boudou A. 2005. Toxicity of selenite in the unicellular green alga Chlamydomonas reinhardtii: Comparison between effects at the population and subcellular level. Aquat Toxicol 73:65-78.

10. Morlon H, Fortin C, Adam C, Garnier-Laplace J. 2005. Cellular quotas and induced toxicity of selenite in the unicellular green alga Chlamydomonas reinhardtii. Radioprotection 40:101-106.

11. Stewart AR, Luoma SN, Schlekat CE, Doblin MA, Hieb KA. 2004. Food web pathway determines how selenium affects aquatic ecosystems: A San Francisco Bay case study. Environ Sci Technol 38:4519-4526.

12. Besser JM, Canfield TJ, La Point TW. 1993. Bioaccumulation of organic and inorganic selenium in a laboratory food chain. Environ Toxicol Chem 12:57-72.

13. Zhang GH, Hu MH, Huang YP. 1990. Se uptake and accumulation in marine phytoplankton and transfer of Se to the clam Puditapes philippnarum. Mar Environ Res 30:179-190.

14. Vandermeulen JH, Foda A. 1988. Cycling of selenite and selenate in marine phytoplankton. Mar Biol 98:115-123.

15. Riedel GF, Ferrier DP, Sanders JG. 1991. Uptake of selenium by freshwater phytoplankton. Water Air Soil Pollut 57-58:23-30.

16. Riedel GF, Sanders JG. 1996. The influence of $\mathrm{pH}$ and media composition on the uptake of inorganic selenium by Chlamydomonas reinhardtii. Environ Toxicol Chem 15:1577-1583.

17. Simkiss K, Taylor MG. 1995. Transport of metals across membranes. In Tessier A, Turner DR, eds, Metal Speciation and Bioavailability in Aquatic Systems. John Wiley, New York, NY, USA, pp 1-44.

18. Wang W, Dei RCH. 2001. Influences of phosphate and silicate on $\mathrm{Cr}(\mathrm{VI})$ and $\mathrm{Se}(\mathrm{IV})$ accumulation in marine phytoplankton. Aquat Toxicol 52:39-47.

19. Yu RQ, Wang WX. 2004. Biokinetics of cadmium, selenium, and zinc in the freshwater alga Scenedesmus obliquus under different phosphorus and nitrogen conditions and metal transfer to Daphnia magna. Environ Pollut 129:443-456.

20. Yu RQ, Wang WX. 2004. Biological uptake of Cd, Se(IV), and $\mathrm{Zn}$ by Chlamydomonas reinhardtii in response to different phosphate and nitrate additions. Aquat Microb Ecol 35:163-173.

21. Sunda WG, Huntsman SA. 1998. Processes regulating cellular 
metal accumulation and physiological effects: Phytoplankton as model systems. Sci Total Environ 219:165-181.

22. Harris EH. 1988. The Chlamydomonas Source Book: A Comprehensive Guide To Biology and Laboratory Use. Academic, San Diego, CA, USA.

23. Denison F. 2004. Uranium(VI) speciation: Modeling, uncertainty, and relevance to bioavailability models. Application to uranium uptake by the gills of a freshwater bivalve. $\mathrm{PhD}$ thesis. Université de Provence, Aix Marseille, France.

24. Organisation for Economic Cooperation and Development-Nuclear Energy Authority. 1996. Survey of thermodynamic and kinetic databases. Paris, France.

25. Martell AE, Smith RM, Motekaitis RJ. 2001. NIST critically selected stability constants of metal complexes database. NIST standard reference database 46, Version 6.0. National Institute of Standards and Technology, Gaithersburg, MD, USA.

26. Pettit LD, Powell HK. 2001. Stability constants database. Academic Software and the Royal Society of Chemistry, Yorks, UK.

27. Williams MJ, Ogle RS, Knight AW, Burau RG. 1994. Effects of sulfate on selenate uptake and toxicity in the green alga Selenastrum capricornutum. Arch Environ Contam Toxicol 27:449453.

28. Wang W, Dei RCH. 2001. Effects of major nutrient additions on metal uptake in phytoplankton. Environ Pollut 111:233-240.

29. Fortin C, Campbell PGC. 2000. Silver uptake by the green alga Chlamydomonas reinhardtii in relation to chemical speciation: Influence of chloride. Environ Toxicol Chem 19:2769-2778.

30. Baines SB, Fisher NS. 2001. Interspecific differences in the bioconcentration of selenite by phytoplankton and their ecological implications. Mar Ecol Prog Ser 213:1-12.

31. Hall J, Healey FP, Robinson GGC. 1989. The interaction of chron- ic copper toxicity with nutrient limitation in two chlorophytes in batch culture. Aquat Toxicol 14:1-13.

32. Garnham GW, Codd GA, Gadd GM. 1992. Uptake of technetium by freshwater green microalgae. Appl Microbiol Biotechnol 37: 679-684.

33. Wrench JJ. 1978. Selenium metabolism in the marine phytoplankters Tetraselmis tetrathele and Dunaliella minuta. Mar Biol 49: 231-236.

34. Ogle RS, Knight AW. 1996. Selenium bioaccumulation in aquatic ecosystems: 1. Effects of sulfate on the uptake and toxicity of selenate in Daphnia magna. Arch Environ Contam Toxicol 30: 274-279.

35. Lortie L, Gould WD, Rajan S, McCready RGL, Cheng KJ. 1992. Reduction of selenate and selenite to elemental selenium by a Pseudomonas stutzeri isolate. Appl Environ Microbiol 58:40424044.

36. Krijger GC, Kollöffel C, Wolterbeek HT. 2000. Effect of nitrate on uptake of pertechnetate by tomato plants. J Environ Qual 29: 866-870.

37. Elrashidi MA, Adriano DC, Workman SM, Lindsay WL. 1987. Chemical equilibria of selenium in soils: A theoretical development. Soil Sci 144:141-152.

38. Sharmasarkar S, Reddy KJ, Vance GF. 1996. Preliminary quantification of metal selenite solubility in aqueous solutions. Chemical Geology 132:165-170.

39. Seby F, Potin-Gautier M, Giffaut E, Borge G, Donard OFX. 2001. A critical review of thermodynamic data for selenium species at $25^{\circ} \mathrm{C}$. Chemical Geology 171:173-194.

40. Essington ME. 1988. Estimation of the standard free energy of formation of metal arsenates, selenates, and selenites. Soil Sci Soc Am J 52:1574-1579. 